\title{
MONOCLONAL ANTIBODIES TO SPECIFIC ASTROGLIAL AND NEURONAL ANTIGENS REVEAL THE CYTOARCHITECTURE OF THE BERGMANN GLIA FIBERS IN THE CEREBELLUM ${ }^{1}$
}

\author{
ANGEL L. DE BLAS \\ Department of Neurobiology and Behavior, State University of New York at Stony Brook, Stony Brook, New York 11794
}

Received May 11, 1983; Revised August 22, 1983; Accepted August 22, 1983

\begin{abstract}
The cytoarchitecture of the cerebellar Bergmann fibers in the adult rat was investigated. Two monoclonal antibodies, one specific for the Bergmann fibers and astrocyte processes and the other specific for the cell bodies and dendrites of the Purkinje cells as well as an antiserum to the glial fibrillary acidic protein, were used in immunocytochemical peroxidase-antiperoxidase assays.

The Bergmann fibers are revealed as columns organized in long vertical palisades parallel to the longitudinal plane of the folium. The palisades are not continuous; instead they are formed by sets of two to six aligned Bergmann fibers. Each of these sets of Bergmann fibers is separated from its longitudinally aligned neighbors by gaps. Each Bergmann fiber is formed by a bundle of two to four Bergmann glia processes which frequently show a helical organization.

These results help to reconcile the different views on the organization of the Bergmann fibers derived from the studies done with the light microscope versus those done with the electron microscope. The Bergmann glia may play a fundamental role in directing the geometrical organization of the cerebellar constituents.
\end{abstract}

Ramón y Cajal (1911, vol. II, pp. 1-106) described the histology of the cerebellum and the geometrical arrangement, orientation, and development of its cellular constituents. This and other studies (i.e., Braitenberg and Atwood, 1958; Eccles et al., 1967; Palay and Chan-Palay, 1974 ) indicate that the dendritic arborization of each Purkinje cell has a planar configuration and is oriented in the transverse plane of the folium. This orientation is also shared by the axons and dendrites of the stellate and basket neurons. In contrast, the parallel fibers which are formed by the axons of the granule neurons are oriented in the longitudinal plane of the folium. Thus the parallel fibers are perpendicular to the dendritic trees of the Purkinje cells.

Much less attention has been focused on the geometrical organization of the Bergmann glia. These cerebellar cells have their cell bodies in the Purkinje cell layer and their fibers (Bergmann fibers) oriented radially through

${ }^{1}$ I wish to thank Holly M. Cherwinski for her excellent technical help. I also thank Dr. Harvey Karten for the use of some of his laboratory facilities and for his comments and discussions. I am grateful to Stephen Mernoff and Linda Cerracchio for their help in the preparation of the manuscript. This research was supported by Grant NS 17708 from the National Institute of Neurological and Communicative Disorders and Stroke and by a Basil O'Connor starter research grant from the National Foundation-March of Dimes. the molecular layer perpendicular to the pial surface. Ramón y Cajal (1911, vol. II, p. 70) noticed that the Bergmann fibers are organized in parallel palisades. This model was supported later by the immunofluorescence studies of Bignami and Dahl (1974a, Fig. 6) using an antiserum to the glial fibrillary acidic protein (GFAP). Altman's (1975) results also supported Ramón y Cajal's interpretation. However, the palisade organization of the Bergmann fibers was not reported in studies on cerebellar preparations examined with the electron microscope (i.e., Rakic, 1971; Swarz and Del Cerro, 1977). Furthermore, Palay and Chan-Palay (1974, p. 299) stated: "ascending processes of neighboring cells (Bergmann glia) are all interdigitated to form a dense forest rather than the alternating or intercalated palisades described by Ramón y Cajal."

In this communication I present a study on the cytoarchitecture of the Bergmann fibers based on differential interference contrast light microscopy immunocytochemistry. I have used a monoclonal antibody specific for Bergmann fibers and astrocyte processes, an antiserum to GFAP, and a monoclonal antibody specific for the Purkinje cell bodies and dendrites. These results show that (i) the Bergmann fibers are organized in palisades, and (ii) these palisades are parallel to the longitudinal plane of the folium. A model for the cytoarchitectural organization of the Bergmann fibers is pre- 
sented. I have also made an attempt to reconcile the apparent discrepancies among the results obtained with the light and electron microscopes. I believe that the discrepancies result from using the name Bergmann fiber for describing two different structures. Each of the Bergmann fibers described by the light microscopists is formed by a bundle of thin Bergmann processes. These Bergmann processes were also called Bergmann fibers by the electron microscopists.

\section{Materials and Methods}

The monoclonal antibodies $8-9 \mathrm{G} 7$ and $8-6 \mathrm{~A} 2$ were obtained after immunizing BALB/c mice with synaptosomal plasma membranes from the rat cerebral cortex (A. L. de Blas, R. O. Kuljis, and H. M. Cherwinski, submitted for publication). They were produced according to the method described by De Blas et al. (1981) using the myeloma line P3X63Ag8. For immunocytochemistry, Sprague-Dawley rats were perfused with periodate/lysine/4\% paraformaldehyde fixative (McLean and Nakane, 1974). Fixed and frozen brains were sliced (25 $\mu \mathrm{m}$ thick) with a microtome. The slices were incubated for 12 to $36 \mathrm{hr}$ at $4^{\circ} \mathrm{C}$ with $8-9 \mathrm{G} 7$ or $8-6 \mathrm{~A} 2$ hybridoma culture medium to which Triton X-100 was added to a final concentration of $0.3 \%(\mathrm{v} / \mathrm{v})$. The rabbit antiserum to GFAP was used at a dilution of $1: 5,000$ with $0.3 \%$ Triton X-100 in $0.1 \mathrm{M}$ phosphate buffer, $\mathrm{pH} 7.4$. The tissue slices were then sequentially incubated with rabbit anti-mouse IgG serum diluted 1:100 (or goat antirabbit IgG for slices treated with rabbit antiserum to GFAP) and mouse (or rabbit for anti-GFAP) peroxidaseantiperoxidase complex (PAP) diluted 1:100, each for 45 min at $22^{\circ} \mathrm{C}$. The dilutions were done with $0.3 \%$ Triton $\mathrm{X}-100$ in $0.1 \mathrm{M}$ phosphate buffer, $\mathrm{pH} 7.4$, and the washes with the same buffer without Triton X-100. The peroxidase reaction was developed with $0.05 \%(\mathrm{w} / \mathrm{v})$ diaminobenzidine tetrahydrochloride, $0.01 \% \quad(\mathrm{v} / \mathrm{v}) \quad \mathrm{H}_{2} \mathrm{O}_{2}$, $0.03 \%(\mathrm{w} / \mathrm{v})$ cobalt chloride, and $0.03 \%(\mathrm{w} / \mathrm{v})$ nickel ammonium sulfate in $0.1 \mathrm{M}$ phosphate buffer, $\mathrm{pH} 7.4$, at $22^{\circ}$. The nickel and cobalt ions were used for intensification of the enzymatic reaction (Adams, 1981). The tissue sections were mounted on glass slides and incubated with $0.05 \% \mathrm{OsO}_{4}$ for 15 sec. The conditioned culture medium of the parental myeloma P3X63Ag8 and a nonimmune rabbit antiserum were used for controls. The tissue sections processed with the control antibodies showed no immunocytochemical staining. When indicated, the mounted sections were counterstained with acidic cresyl violet ( $5 \mathrm{gm} / \mathrm{liter}$ ) for $2 \mathrm{~min}$ at $22^{\circ} \mathrm{C}$. The rabbit antiserum to GFAP was the generous gift of Drs. Amico Bignami and Doris Dahl from the West Roxbury Veterans Administration Hospital (Boston). Mouse PAP was purchased from Sternberger-Meyer (Jarrettsville, MD). Rabbit PAP was from Miles-Yeda (Elkhart, IN), and rabbit anti-mouse IgG and goat anti-rabbit IgG were from Cappel (Cochranville, PA).

\section{Results}

Three different antibodies have been used in these studies: $(i)$ a monoclonal antibody (8-9G7) that binds specifically to Bergmann glia and astrocytes, (ii) a rabbit antiserum to GFAP that is also specific for Bergmann glia and astrocytes (Dahl and Bignami, 1973), and (iii) a monoclonal antibody (8-6A2) which in the cerebellum specifically recognizes Purkinje cell bodies and dendrites.

Figure 1 shows the reactivity of these antibodies with the cerebellum. The monoclonal antibody 8-9G7 (Fig. 1, $B$ and $D$ ) and the antiserum to GFAP (Fig. $1 E$ ) show a similar pattern of reactivity; both recognize Bergmann fibers and astrocyte processes. Nevertheless, 8-9G7 binds to a cytoskeleton molecule other than GFAP which is specifically found in these glial cells (A. L. de Blas, R. O. Kuljis, and H. M. Cherwinski; submitted for publication). It should also be noticed that most of the stained elements in the molecular layer are Bergmann fibers. There are also a few astrocyte processes that have their cell bodies in the granular cell layer (see also Bignami et al., 1980). In contrast, the monoclonal antibody 8-6A2 in the cerebellum binds specifically to the cell bodies and main dendrites of the Purkinje cells (Fig. 1, $A$ and $C$ ). No other cerebellar structures bind this antibody.

Bergmann glia fibers are organized in parallel palisades. Figure 2 shows horizontal sections (parallel to the pial surface) of the molecular layer of the cerebellum stained with the antibody 8-9G7. In Figure $2 D$ the antiserum to GFAP was used instead. The stained elements are segments of the Bergmann fibers.

These results indicate that the Bergmann fibers are organized in parallel palisades of columns. The columns are generally organized in sets (of two to six aligned columns). These sets are aligned and separated from each other by a gap of $9 \mu \mathrm{m}$ (average value). The columns are seen as dots in the sections that are perfectly perpendicular to the Bergmann fibers (Fig. 2, $A, C$, and $D$ ). The distance between two parallel palisades has an average value of $9.5 \mu \mathrm{m}$. When the sections are not perfectly perpendicular to the Bergmann fibers it can be seen that each column (or Bergmann fibers to the light microscopists) is composed of several closely packed Bergmann processes (Fig. 2, $B, E$, and $F$ ). Figure $2 F$ shows that the Bergmann fibers and processes are frequently twisted and curled forming helical structures (see also Figs. 1, $D$ and $E$ and $3 B$ ).

Figure $3 A$ shows the distribution of the neuronal cell bodies in the molecular layer with respect to the Bergmann fiber palisades. Figure $3 B$ shows some important features of the organization of these fibers (see also Fig. 1, $D$ and $E$ ): (i) The Bergmann fibers are straight columns that extend from near the Purkinje cell body layer to the pial surface. (ii) Sometimes some of the Bergmann processes of a Bergmann fiber can separate from the rest and join the strands of an adjacent fiber (Fig. 3B). (iii) The Bergmann processes that abandon a fiber do not stay alone; instead they tend to join adjacent fibers.

Bergmann fiber palisades are parallel to the longitudinal plane of the folium. We have also determined the orientation of the Bergmann fiber palisades by studying their orientation with respect to the Purkinje cell dendritic trees. Figure $4 A$ shows a cerebellar horizontal section stained with the monoclonal antibody 8-9G7 (specific for Bergmann fibers), whereas Figure $4 B$ shows the same area of a consecutive section that has been stained with 

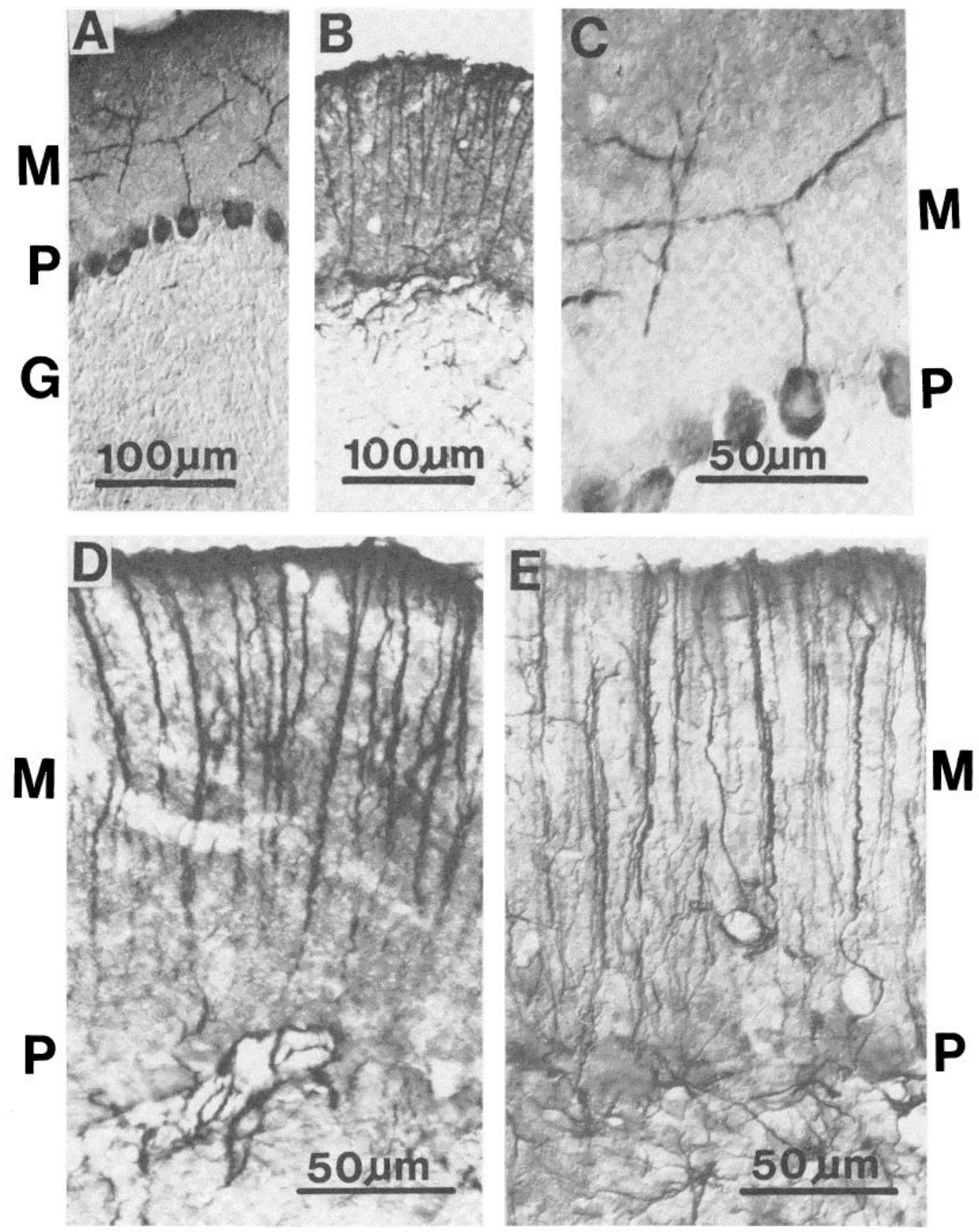

Figure 1. Cerebellum immunocytochemistry (sagittal sections, transverse to the folium) with the monoclonal antibodies 8-6A2 $(A$ and $C)$ and 8-9G7 $(B$ and $D)$ and with the anti-GFAP antiserum $(E)$. Differential interference-contrast optics. $M$, molecular layer; $P$, Purkinje cell body layer; $G$, granule cell layer. The rats were 35 days old in $A$ and $C$ and 60 days old in $B, D$, and $E$. The antibody 8-6A2 specifically stains the cell bodies and main dendrites of the Purkinje cells. The antibodies 8-9G7 $(B$ and $D)$ and anti-GFAP $(E)$ both recognize Bergmann fibers and astrocyte processes.

the antibody 8-6A2 (which is specific for the main Purkinje cell dendrites). Figure $4 C$ shows a different area of a third section stained with antiserum to GFAP. Figure $4 D$ shows the same area as $4 C$ of a consecutive section stained with 8-6A2. Figure 5 shows a horizontal section of the molecular layer of the cerebellum that has been simultaneously stained with both monoclonal antibodies 8-9G7 and 8-6A2.

Figures 4 and 5 show that the Bergmann glia palisades are perpendicular to the plane of the Purkinje dendritic trees. It is well known that the Purkinje dendritic trees are perpendicular to the longitudinal plane of the folium 

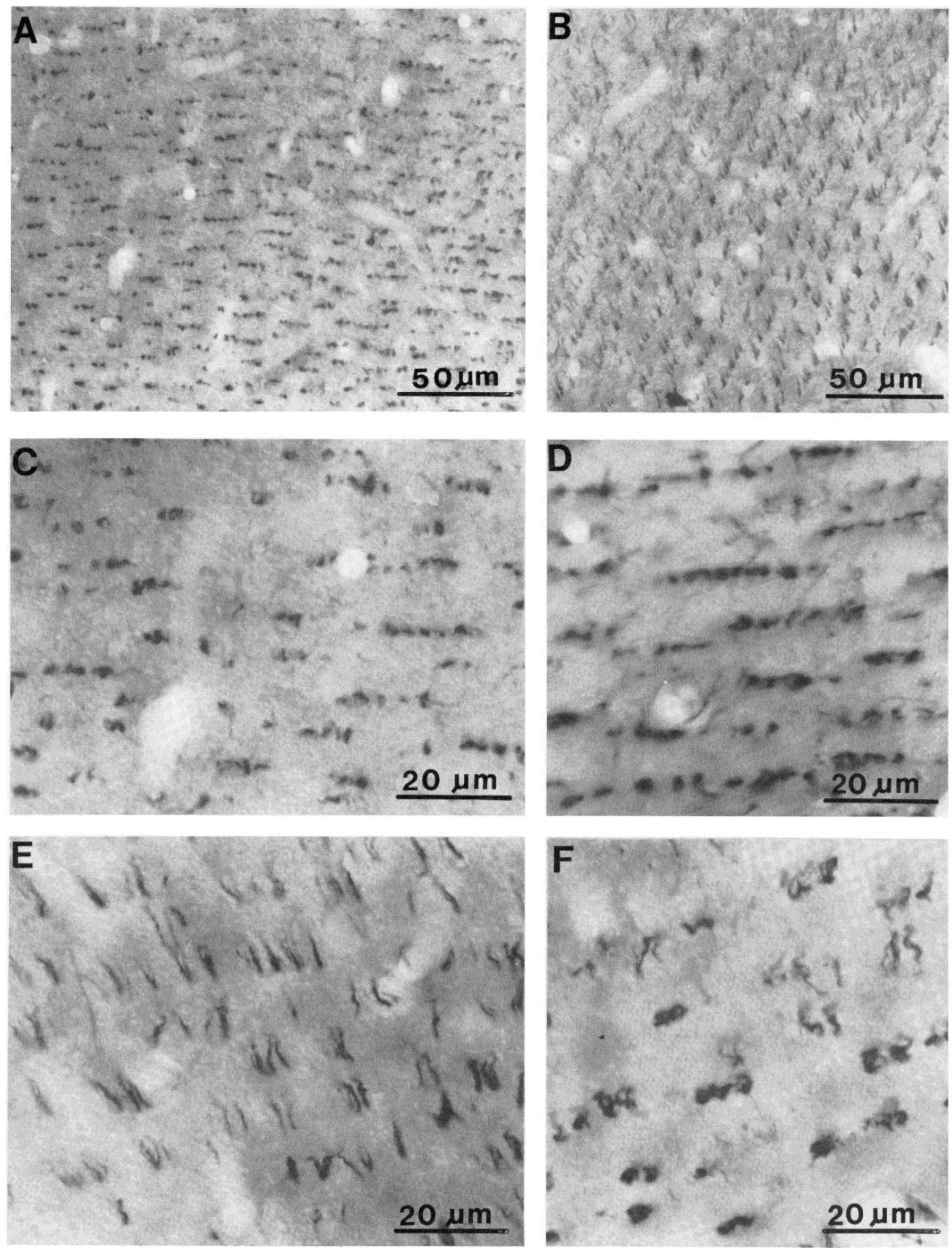

Figure 2. Immunocytochemistry of the molecular layer of the cerebellum (horizontal sections) with the monoclonal antibody 8-9G7 $(A, B, C, E$, and $F)$ and the anti-GFAP antiserum $(D)$. Sections are from 35-day-old rat, except for $D$ which is 60 days old. Differential interference-contrast optics. Notice the arrangement of the Bergmann fibers in parallel palisades. 

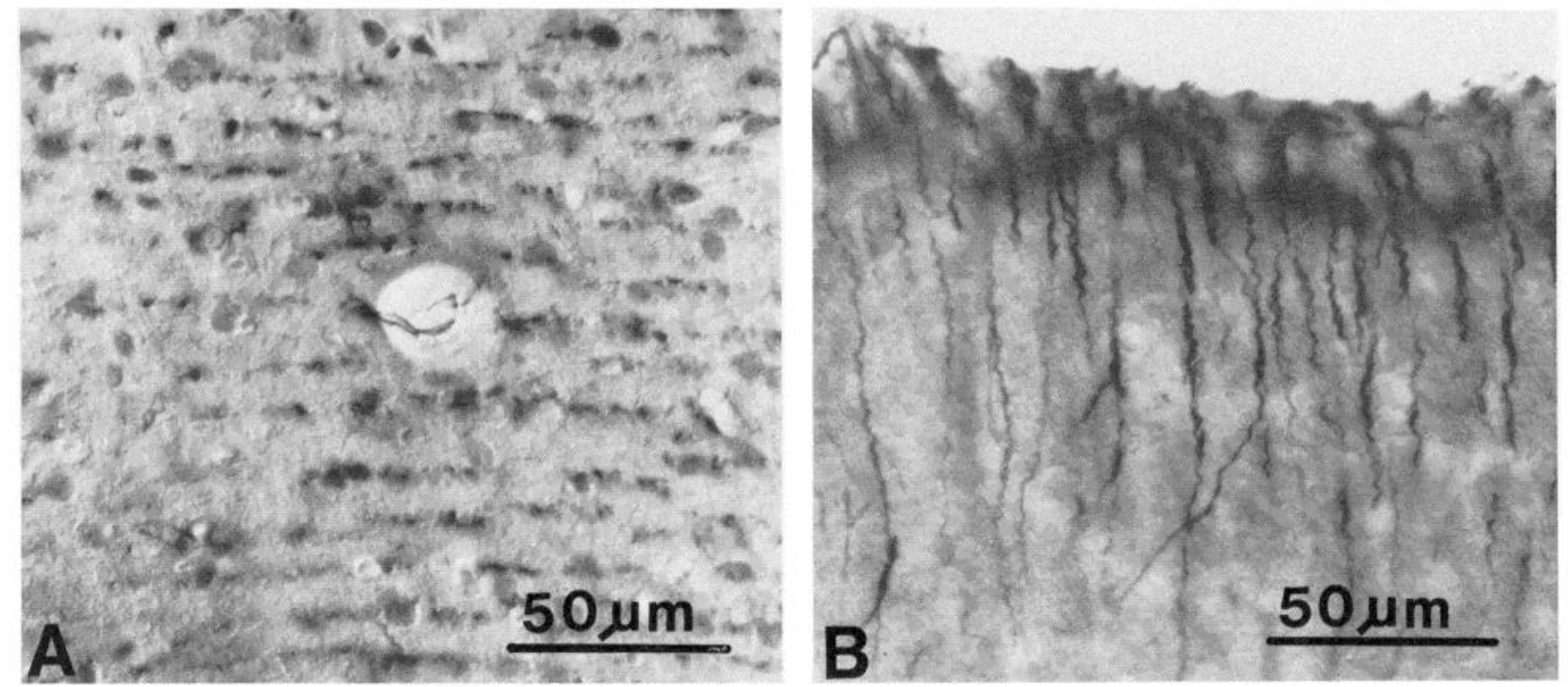

Figure 3. Cerebellum immunocytochemistry with antiserum to GFAP $(A)$ on a 60-day-old rat and with monoclonal antibody 8-9G7 $(B)$ on a 30-day-old rat. $A$ shows a horizontal section counterstained with cresyl violet for staining of the neuronal cell bodies. $B$ is a sagittal section. Differential interference-contrast optics. Notice in $B$ the helical aspect of many of the Bergmann fibers and the tendency to form bundles.
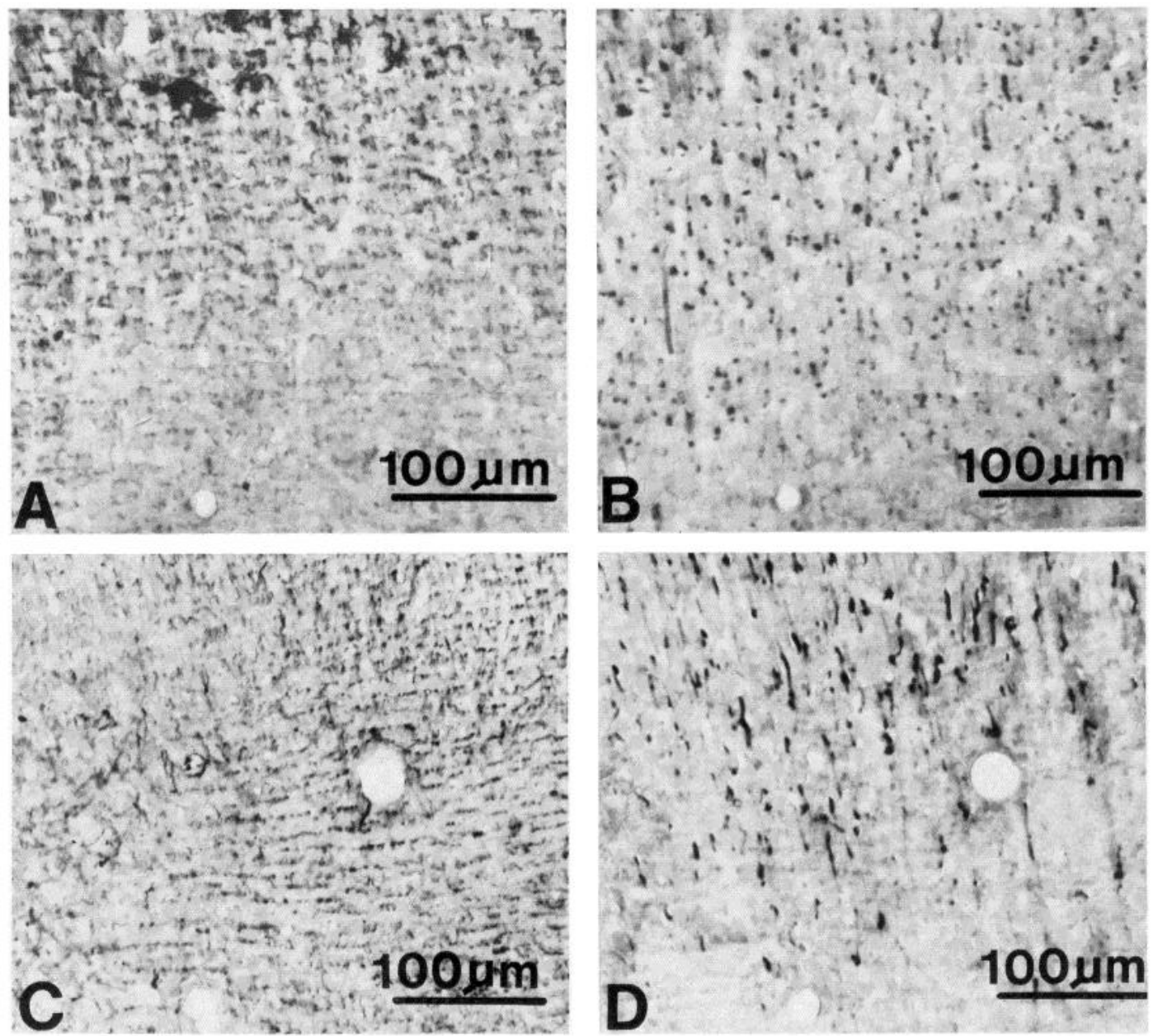

Figure 4. Immunocytochemistry of the molecular layer of the cerebellum (horizontal sections) with the monoclonal antibodies 8-9G7 $(A)$ and 8-6A2 $(B$ and $D)$ and the antiserum to GFAP $(C)$. A and $B$ show the same area of two consecutive sections. $C$ and $D$ also show the same area of two consecutive sections, but the area presented in $A$ and $B$ is different than the area shown in $C$ and $D$; 60-day-old rat. Differential interference-contrast optics. Notice the horizontal alignment of the Bergmann fiber palisades $(A$ and $C$ ) and the vertical orientation of the Purkinje dendrites $(B$ and $D)$. 

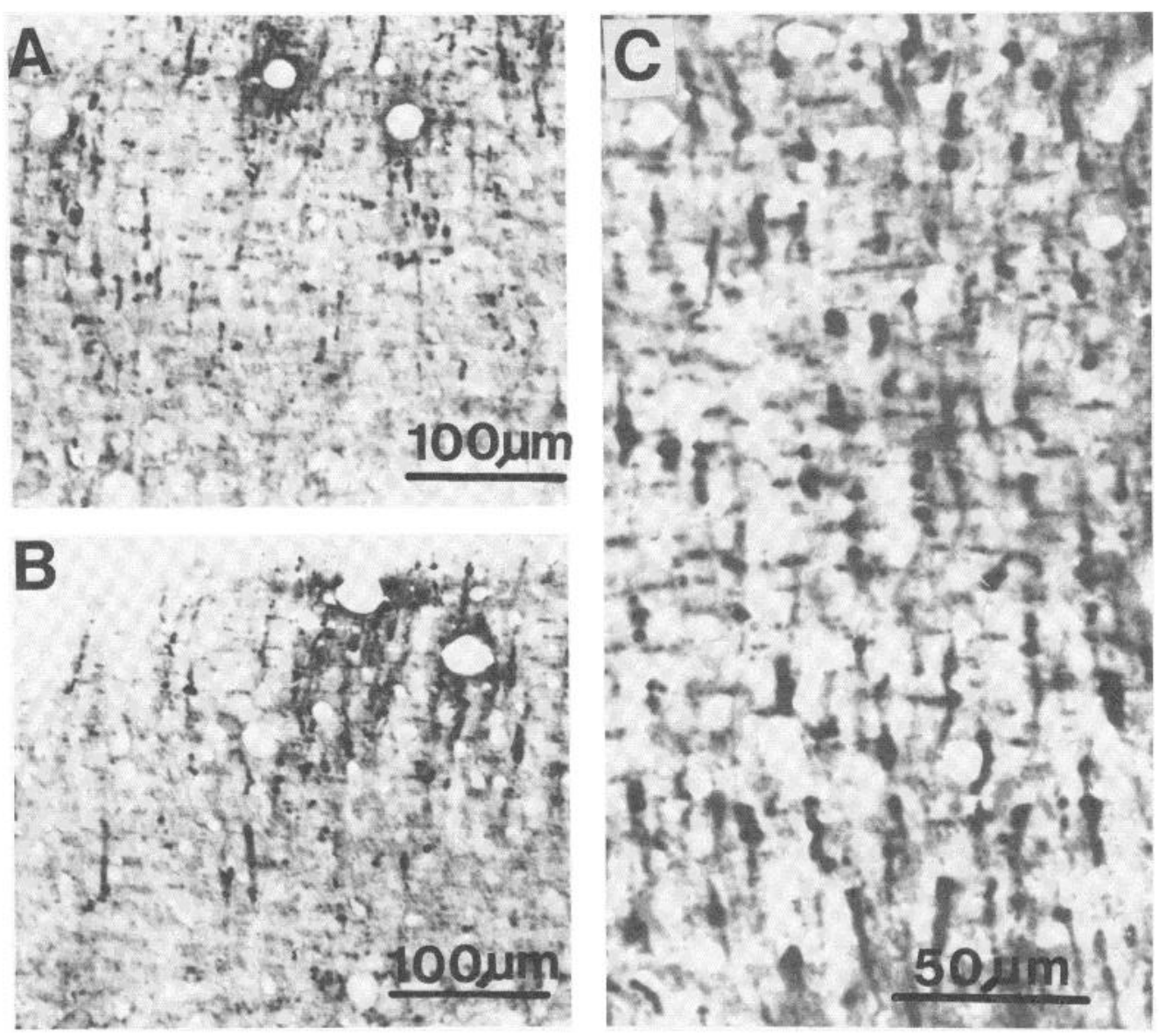

Figure 5. Cerebellum molecular layer immunocytochemistry (horizontal sections). The tissue slice from a 60 -day-old rat was incubated simultaneously with both monoclonal antibodies 89G7 and 8-6A2. $A, B$, and $C$ are different areas of the same section. Differential interferencecontrast optics. Notice the horizontal alignment of the Bergmann fiber palisades and the vertical orientation of the thicker Purkinje cell dendrites.

(Ramón y Cajal, 1911, vol. II, p. 3-18; Braitenberg and Atwood, 1958). We can then safely conclude that the Bergmann fiber palisades are parallel to the longitudinal plane of the folium.

\section{Discussion}

These results confirm Ramón y Cajal's original description of the organization of the Bergmann fibers in palisades. Altman (1975) has proposed that the nonstained or empty spaces seen in the molecular layer of the cerebellum, after the staining of this tissue with Bodian's protargol-S, are occupied by the Bergmann fiber palisades. These empty spaces were oriented in the longitudinal plane of the folium. Altman also proposed that these empty spaces correspond to the parallel structures seen by Bignami and Dahl (1974a) after anti-GFAP immunofluorescence. The two major problems in accepting Altman's interpretation are: (i) Bignami and Dahl (1974a) did not indicate the orientation of the Bergmann fiber palisades that they observed, and (ii) Altman's results were based on the probably correct but unproven assumption that the Bergmann fibers were the only structures of the molecular layer that remained nonstained after using Bodian's technique. Our results provide direct supportive evidence of Altman's suggestion.
There is also another study dealing with the orientation of the Bergmann fiber palisades which is the work of Ramón y Cajal, who discovered and described these structures. Unfortunately, this reference does not help in resolving the issue of the orientation of the palisades. We believe that this is due to an erratum in the text. The text indicates that the palisades are perpendicular to the longitudinal plane of the folium (Ramón y Cajal, 1911, vol. II, p. 70), ${ }^{2}$ whereas the accompanying figure (Fig. 51) shows that the palisades are parallel to the longitudinal plane of the folium. The results that I present here (see below) indicate that the figure is correct and the text is not.

I have addressed the issue of the orientation of the Bergmann fiber palisades by studying their orientation relative to the Purkinje cell dendrites. For this purpose I have done the immunocytochemical analysis of the molecular layer of the cerebellum. I have compared the

\footnotetext{
2 "Lorsqu'on examine attentivement les expansions des cellules epitheliales" (Bergmann fibers) "sur des coupes paralleles a l'axe longitudinal des circonvolutions cerebelleuses, on apprend qu'elles forment des plans ou feuillets superposés, perpendiculaires a ce grand axe et intercalés entre deux arborisations consecutives de cellules de Purkinje (Fig. 51)."
} 
Bergmann fiber-specific antibodies 8-9G7 (monoclonal) and anti-GFAP (antiserum) with the monoclonal antibody 8-6A2 which specifically binds to the cell bodies and major dendrites of the Purkinje cells. These studies using horizontal sections of the cerebellar molecular layer indicate that the Bergmann fiber palisades and the Purkinje dendritic trees are perpendicular to each other (Figs. 4 and 5). This means that the Bergmann fiber palisades are parallel to the longitudinal plane of the folium.

The results also show what was already seen with the Golgi method (Ramón y Cajal, 1911, vol. II, p. 70) - that most of the Bergmann fibers are straight columns that go from the vicinity of the Bergmann glia cell bodies to the pial surface (Figs. 1, D and $E$ and $3 B$ ). Each fiber is formed by a bundle of processes. When some of these processes separate from the bundle they cluster again with the strands of a neighboring bundle (Fig. $3 B$ ). This tendency to form bundles may represent some sort of chemoaffinity between the Bergmann processes.

The Bergmann fiber palisades have gaps that separate aligned sets of two to six fibers (four fibers average). Each gap probably separates the Bergmann fibers that have their origin in two adjacent Bergmann glia cells. These gaps very likely contain the main dendritic branches of the intercalated Purkinje cells (Ramón y Cajal, 1911, vol. II, p. 70). Each Bergmann glia cell projects its fibers in both the longitudinal and transverse planes of the folium; however, it is known that the domain of each Bergmann glia cell is larger in the transverse plane (i.e., Altman, 1975). 'The domain of each Bergmann glia extends to 40 to $50 \mu \mathrm{m}$ in the transverse plane of the folium (i.e., Palay and Chan-Palay, 1974, p. 289 ) and 8 to $20 \mu \mathrm{m}$ in the longitudinal plane. The dendritic tree of a Purkinje cell extends 300 to $400 \mu \mathrm{m}$ in the transverse plane of the folium and 15 to $20 \mu \mathrm{m}$ in the longitudinal plane (Palay and Chan-Palay, 1974, p. 32 ). It is then concluded that the dendritic domain of each Purkinje cell can expand to the domains of up to 7 to 10 Bergmann glia cells in the transverse plane of the folium. The main branches of the Purkinje dendritic trees are probably localized within the $9-\mu \mathrm{m}$ palisade gaps, while the minor branches penetrate the territory occupied by the Bergmann fibers.

A very schematic and simplified illustration of the cytoarchitecture of the Bergmann fibers is shown in Figure 6. The bottom of this figure represents a horizontal section of the molecular layer. Compare this figure with Figure 5 after rotating Figure 6 through $90^{\circ}$.

The parallel corridors existing between the Bergmann fiber palisades must be occupied mainly by the parallel fibers and by the cell bodies of the stellate and basket neurons (Fig. $3 A$ ). It seems then that the width of each of these corridors would allow the passage of layers of 20 to 40 parallel fibers $(0.25$ to $0.5 \mu \mathrm{m}$ diameter each).

These results also show that each Bergmann fiber is composed of a cluster of thin Bergmann processes. These processes frequently curl and twist forming helical structures (Figs. 1, $D$ and $E ; 2 B, E$, and $F ; 3 B$ ). The number and arrangement of the processes vary, but normally we can see two to four processes in each Bergmann fiber.

These results also bridge the different views of the organization of the Bergmann fibers derived from the studies done with the light microscope and the electron microscope. The Bergmann fibers (stained with the Golgi method) are seen with the light microscope as solid cylindrical columns well separated from the other fibers. They have beady enlargements and bushy lamellar expansions (Ramón y Cajal, 1911, vol. II, p. 70; Rakic, 1971). With the electron microscope the Bergmann fibers
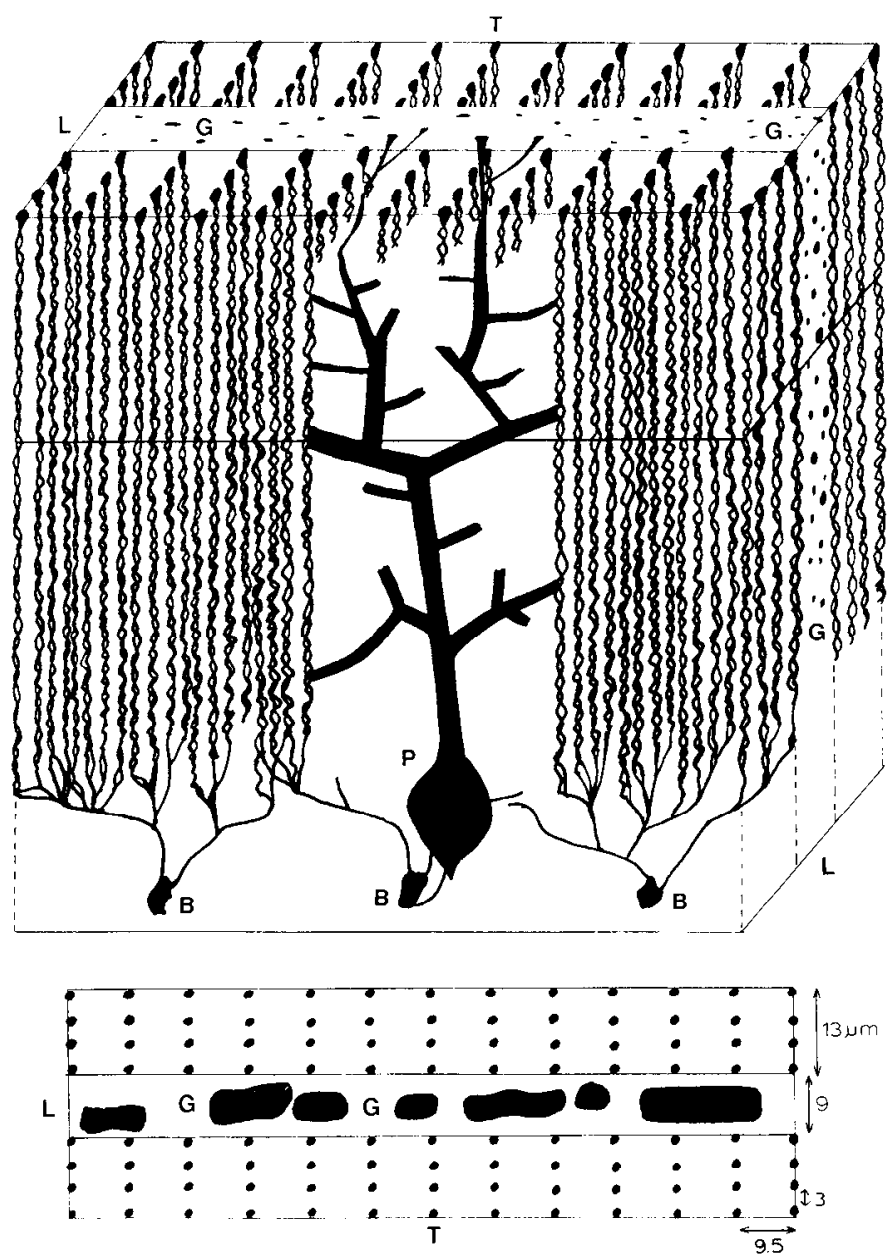

Figure 6. Schematic and simplified illustration of the cytoarchitecture of the Bergmann fibers. $B$, the Bergmann glia cell bodies. $P$, a Purkinje cell showing the main branches of its dendritic tree. $G$ indicates the gap, and $L$ and $T$ show the direction of the longitudinal and transverse plane of the folium, respectively. The Bergmann fibers have endfeet on the pial surface. The fibers are organized in palisades that are parallel to the longitudinal plane of the folium. There are also transverse gaps where the main branches of the Purkinje dendritic trees are localized. Notice that some fibers are formed by processes originating in two adjacent Bergmann glia cells. A longitudinal row of Bergmann fibers between two consecutive gaps contains two to six of these tibers. For simplicity we have represented all the rows with four fibers (average value) and each fiber with two processes. The value of the thickness of the gap is also an average value $(9 \mu \mathrm{m})$. During the growth and shaping of the cerebellum, some distortions of the basic pattern are created and more complicated arrays often can be observed (see Fig. 2). The bottom of this figure shows a schematic representation of a horizontal section of the molecular layer. Compare this scheme with Figure 5. Notice that in Figure 5 the longitudinal plane of the folium is in the horizontal direction, whereas in Figure 6 it is in the vertical direction. 
are often seen twisted and folded. Sometimes several fibers may run together as closely aligned sheaves (Rakic, 1971). These fibers are very thin $(0.2$ to $0.4 \mu \mathrm{m}$ in diameter), which contrasts with the thick fibers seen by the light microscopists.

Our results suggest that each of the Bergmann fibers $\mathrm{s} r$ en by the light microscopists is formed by a bundle of two to four of the Bergmann fibers seen by the electron microscopists. This interpretation is consistent with the information on the organization and dimensions of the Bergmann fibers obtained from the immunocytochemical experiments presented here. Thus the apparent contradictory results obtained by the light versus electron microscopists is due to using the same name (Bergmann fiber) to describe two different structures. I suggest using the name Bergmann fiber when referring to the structures that originally received such a name from the light microscopists (Ramón y Cajal, 1911, vol. II, p. 70). I also prefer to use the name Bergmann processes for the components of each Bergmann fiber.

The immunocytochemical technique using the antibodies 8-9G7 and anti-GFAP (see also Bignami and Dahl, 1974a) does not show the beady enlargements and bushy lamellar expansions of the Bergmann fibers seen with the Golgi method and with the electron microscope (Ramón y Cajal, 1911, vol. II, p. 70; Rakic, 1971). This is probably due to the binding of these antibodies to cytoskeletal glial filaments (A. L. de Blas, R. O. Kuljis, and H. M. Cherwinski, submitted for publication) which bypass these structures (Rakic, 1971). I also believe that the columnar organization of the Bergmann fibers and processes described in this study does not preclude the existence of finer horizontal branches that escaped detection.

What are the developmental and/or functional implications of this organization of the Bergmann fibers in parallel palisades? There is a close interaction between the Bergmann fibers and the granule cell bodies during the migration of the latter from the external granule cell layer to the internal granule cell layer. These observations suggest that Bergmann fibers could guide the migrating granule cells across the molecular layer (Mugnaini and Forströnen, 1967; Rakic, 1971). Rakic (1971) has also noticed that the migrating granule cells "spiral" around the stem of the Bergmann fiber. He interpreted this spiraling as necessary for avoiding the lamellate expansions found by the granule cell in its pathway. However, our results suggest a different and simpler explanation-that the spiraling movement of the migrating granule cells reflects the helical arrangement of the Bergmann fibers and processes. The granule cells with a diameter of 1.5 to $3 \mu \mathrm{m}$ (Rakic, 1971) can fit well, without major rearrangements, between two adjacent Bergmann fibers but not between two adjacent processes of the same fiber. The Bergmann glia of the rat cerebellum has been detected with the Golgi method on the first postnatal day (Fulöp et al., 1979), on the fourth postnatal day by immunofluorescence with anti-GFAP (Bignami and Dahl, 1973, 1974a), and even several days before birth (Del Cerro and Swarz, 1976) by electron microscopy. These observations indicate that the Bergmann fibers are present in the cerebellum $(i)$ before the migra- tion of the granule cells, stellate neurons, and basket neurons from the external granule cell layer; and (ii) before the Purkinje cells have developed and oriented their dendritic trees (Addison, 1911; Atlman, 1972a). These results support the proposed guidance function of the Bergmann fibers during the migration of the granule cells (Rakic, 1971).

If the Bergmann fiber palisades are also formed and oriented earlier than the parallel fibers, then the Bergmann glia could possibly have an important role not only in guiding the migrating neurons but also as organizers of the geometrical structure of the cerebellar elements during development. Consistent with this hypothetical role of the Bergmann fibers is the observation that after $x$-ray irradiation of the developing rat cerebellum both the parallel fibers and the glial palisades reorient in the same direction but they no longer remain aligned with the longitudinal plane of the folium (Altman, 1975). Altman (1975) favors the opinion that the formation of the glial palisades is preceded by the alignment of the parallel fibers. Nevertheless, due to the nature of the technique used for identifying Bergmann fibers already discussed above, it is necessary to investigate this hypothesis with the support of the immunocytochemical methods described in this paper. Preliminary results obtained in my laboratory indicate that the Bergmann fiber palisades are already present in the rat at postnatal day 5 . This is long before the peak of granule cell migration and before the development and orientation of the Purkinje cell dendrites (Altman, 1972a, b).

Relevant information on this subject can also be obtained by studying the orientation of the glial fiber palisades in the weaver mouse mutant. These animals have a reduced number of cerebellar granule cells. This results from the death of the granule cells that cannot migrate to the granule cell layer. The Bergmann glia could be the primary target of this mutation. It has been reported that the weaver mutant has an extensive reduction in the number of Bergmann glia (Rakic and Sidman, 1973) or no reduction in the number of these cells but rather shorter and more irregular Bergmann fibers (Bignami and Dahl, 1974b; Sotelo and Changeux, 1974).

\section{References}

Adams, J. C. (1981) Heavy intensification of DAB-based HRP reaction product. J. Histochem. Cytochem. 29: 775.

Addison, W. H. F. (1911) The development of the Purkinje cells and of the cortical layers in the cerebellum of the albino rat. J. Comp. Neurol. 21: 459-487.

Altman, J. (1972a) Postnatal development of the cerebellar cortex in the maturation of Purkinje and of molecular layer. J. Comp. Neurol. 145: 399-464.

Altman, J. (1972b) Postnatal development of the cerebellar cortex in the rat. Maturation of the components of the granular layer. J. Comp. Neurol. 145: 465-514.

Altman, J. (1975) Postnatal development of cerebellar cortex in the rat. Spatial organization of bipolar cells, parallel fibers and glial palisades. J. Comp. Neurol. 163: 427-448.

Bignami, A., and D. Dahl (1973) Differentiation of astrocytes in the cerebellar cortex and the pyramidal tracts of the newborn rat. An immunofluorescence study with antibodies to a protein specific to astrocytes. Brain Res. 49: 393-402.

Bignami, A., and D. Dahl (1974a) Astrocyte-specific protein 
and neuroglial differentiation. An immunofluorescence study with antibodies to the glial fibrillary acidic protein. J. Comp. Neurol. 153: 27-38.

Bignami, A., and D. Dahl (1974b) The development of Bergmann glia in mutant mice with cerebellar malformations: Reeler, Staggerer and Weaver. Immunofluorescence study with antibodies to the glia fibrillary acidic protein. J. Comp. Neurol. 155: 219-229.

Bignami, A., D. Dahl, and D. C. Rueger (1980) Glial fibrillary acidic protein (GFA) in normal neural cells and in pathological conditions. Adv. Cell. Neurobiol. 1: 285-310.

Braitenberg, V., and R. Atwood (1958) Morphological observations on the cerebellar cortex. J. Comp. Neurol. 109: 1-33.

Dahl, D., and A. Bignami (1973) Immunochemical and immunofluorescence studies of the glial fibrillary acidic protein in vertebrates. Brain Res. 61: 279-293.

De Blas, A. L., M. V. Ratnaparkhi, and J. E. Mosiman (1981) Estimation of the number of monoclonal hybridomas in a cell fusion experiment. Effect of post-fusion cell dilution on hybridoma survival. J. Immunol. Methods 45: 109-115.

Del Cerro, M. and J. R. Swarz (1976) Prenatal development of Bergmann glia fibers in rodent cerebellum. J. Neurocytol. 5: $669-676$.

Eccles, J. C., M. Ito, and J. Szentagothai (1967) The Cerebellum as a Neuronal Machine, Springer-Verlag, New York.

Fulöp, Z., J. Lakos, E. Bascó, and F. Hajós (1979) Identification of early glial elements as the precursors of Bergmann glia: A Golgi analysis of the developing rat cerebellar cortex. Acta
Morphol. Acad. Sci. Hung. 27: 273-280.

McLean, I. W., and P. K. Nakane (1974) Periodate-lysineparaformaldehyde fixative. A new fixative for immunoelectron microscopy. J. Histochem. Cytochem. 22: 1077-1083.

Mugnaini, E., and P. F. Forströnen (1967) Ultrastructural studies on the cerebellar histogenesis. I. Differentiation of granule cells and development of glomeruli in the chick embryo. J. Zellforsch. Mikrosk. Anat. Abt. Histochem. 77: $115-143$.

Palay, S. L., and V. Chan-Palay (1974) Cerebellar Cortex, Cytology and Organization, Springer-Verlag, New York.

Rakic, P. (1971) Neuron-glia relationship during granule cell migration in developing cerebellar cortex: A Golgi and electronmicroscopic study in Maccacus rhesus. J. Comp. Neurol 141: $283-312$.

Rakic, P., and R. L. Sidman (1973) Sequence of developmental abnormalities leading to granule cell deficit in cerebellar cortex of weaver mutant mice. J. Comp. Neurol. 152: 103132.

Ramón y Cajal, S. (1911) Histologie du Systeme Nerveux de l'Homme et des Vertebrés, Maloine, Paris. Reprinted by Consejo Superior de Investigaciones Cientificas, Madrid, 1972.

Sotelo, C., and J. P. Changeux (1974) Bergmann fibers and granular cell migration in the cerebellum of homozygous weaver mutant mouse. Brain Res. 77: 484-491.

Swarz, J. R., and M. Del Cerro (1977) Lack of evidence for glial cells originating from the external granular layer in mouse cerebellum. J. Neurocytol. 6: 241-250. 